\title{
Accessibility and Utilization of Tuberculosis Directly Observed Therapy in Primary Health Care Facilities in Katsina State, North West Nigeria
}

\author{
Yahaya Shamsuddeen Suleiman ${ }^{1 *}$, Olorukooba Abdulhakeem Abayomi ${ }^{2}$, Abdurrahman \\ Halima $^{3}$, Sambo Nasir $\mathbf{M}^{2}$ \\ ${ }^{1}$ State Primary Health Care Agency, Katsina, Nigeria \\ ${ }^{2}$ Department of Community Medicine, Ahmadu Bello University, Zaria, Nigeria, \\ ${ }^{3}$ Eye Centre, Katsina State, Nigeria
}

\begin{abstract}
Tuberculosis is a public health problem in Katsina state. Previous effort to decrease the burden of $T B$ was substantially targeted at the secondary and tertiary level of care. The new strategy calls for the decentralization of DOTS at the PHC level. This study assessed the resources for diagnosis and treatment of TB, utilization of services in PHC facilities in Katsina state. The study design was a crosssectional descriptive study and it enrolled 225 TB patients in 32 health facilities through a multi-stage sampling technique. A structured interviewer-administered questionnaire was used to obtain data from respondents. Qualitative data were also collected using KII. The data was analyzed using SPSS version 20-software package. For the qualitative aspect, content analysis was done for KII. Of the Health facilities studied 7 (28\%) were diagnostic centres while 25 (72\%) were treatment (intake) centres. The mean age of TB patients was 39+13 years also the mean duration since the commencement of treatment was 3 months. The mean duration time before reaching the hospital was $39+27$ minutes. The majority (98.5\%) of TB patients had easy access to a health facility. About one third (34.4\%) of the health facilities had and were using a microscope. In conclusion, the study revealed that resources for TB diagnosis were not adequate in most of the health facilities. However, resources for TB treatment were sufficient. The state government should provide more support in making TB resources adequate in all facilities.
\end{abstract}

Keywords: Accessibility, DOTS, Katsina, Primary Health Care, Tuberculosis, Utilization.

\section{Introduction}

Tuberculosis (TB) is an infectious disease caused by the bacterium Mycobacterium tuberculosis. It typically affects the lungs (pulmonary TB) but can also affect other sites as well (extra-pulmonary TB) [1].

To deal with the growing global TB problem, the World Health Organization (WHO) declared TB as a global emergency and introduced the Directly Observed Treatment Short-Course (DOTS) strategy in 1994 [2]. The aim of introducing DOTS was to achieve the set targets (to detect $70 \%$ new TB cases and cure $85 \%$ of those detected successfully) and to halve global TB prevalence and deaths by 2015 , relative to the 1990s levels [2].

Nigeria adopted the WHO Directly Observed Treatment Short Course (DOTS) strategy to control the disease in 1993.
The treatment of TB has constituted a major problem in Nigeria for several reasons. First Many people with TB are still not detected and they are not able to access the treatment. Second, the number of new cases of TB is increasing in the country because of the epidemic of HIV/AIDS. Awareness among the communities, especially the leadership of the communities and the citizens about TB, its manifestation, its causes, and modalities for treatment is poor [3].

Although Nigeria receives huge support from donor agencies like WHO and UNDP, there is a wide gap between the resources needed and what is provided. Long distance to the hospitals which limits the chances of patients' financing their treatment, lack of facility for a home visit in most cases and poor supervision in under-aged children are some of the contributing factors for high treatment default rate which often results in the development of multidrug-resistant TB [4]. 
The major challenges to DOTS implementation especially at the PHC level is the low political commitment, especially at the LGA level. The health system that should provide the platform for the delivery of DOTS services is extremely weak at the PHC level and non-availability of skilled health workers and dearth of laboratory services [5].

In Katsina state, TB is still a public health problem with an existing but weakly functioning state TBL control programs with inadequate planning and low-level implementation [6]. There has been limited advocacy on implementation, DOTS service coverage, low tracing capacity and inadequate collaboration with other service providers. Previous effort to decrease the burden of TB was substantially targeted at the secondary and tertiary level of care. The new strategy calls for decentralization of DOTS in PHC Level. Information about the access and utilization of TB services at PHC level will help to provide a basis for improved policies and planning, which could help to foster better TB control in the state. We carried out this study to determine the accessibility and utilization of TB DOTS in PHC settings in Katsina State.

\section{Materials and Methods}

\section{Study Area}

Katsina state is located between latitude $11.7^{0}$ and $13.32^{\circ} \mathrm{N}$ and between longitude $6.52^{\circ}$ and $9.02^{0} \mathrm{E}$. The state shares border with Zamfara and Sokoto state in the west, Kano and Jigawa state in the east, Kaduna state in the south and Niger republic in the north. It has an area of 23,938 square kilometers and a projected population of 5,801,419 based on 2006 census with a projected growth rate of $3.0 \%$ per annum [7].

There are 184 TB DOTS centres, 23 microscopy centres and a functional TB HIV working group which was established in January 2008 in the state. All of the 34 LGAs provide TB DOTS services, of which 20 have state advocacy committees [8]. There are 160 PHC facilities providing TB DOTS Services, including private facilities which are spread across the 34 LGAs and nearly half of the political wards. The drugs and Laboratory investigations are provided free of charge. There are an estimated 8081patients with all forms of TB with case notification rate of 34 per 100,000 . The incidence rate of all forms of TB was 32 and total cases of 2332 with Crude Death Rate of 29\% [8].

The TB control team is structured according to the national guideline for $\mathrm{TB}$ and leprosy control programmed (NTBLCP) in Nigeria. At the state level is the state TB and Leprosy control officer (STBLCO) supported by State TB and Leprosy Supervisors (STBLS). They are responsible for planning, supervision, monitoring and evaluation of the TB activities at the operational levels. They are also responsible for training of personnel in TB control services and offering of technical and logistic supports, including advocacy. The LGA is the operational unit; the team at this level includes the LGA TB and Leprosy Supervisor (LGTBLS), the General Health Care Workers (GHCW), the Medical Officer (MO) and the laboratory staff [9].

\section{Study Design}

The research design was a cross-sectional descriptive study.

\section{Study Population}

The study populations were:

i. Pulmonary TB patients who were receiving treatment at $\mathrm{PHC}$ facilities

ii. Local government TB and Leprosy Supervisors.

\section{Inclusion Criteria}

i. All pulmonary TB patients who have spent at least 2 months on treatment.

ii. Local government $\mathrm{TB}$ and Leprosy Supervisors (LGTBLS).

\section{Exclusion Criteria}

i. Health facilities providing PHC service that are privately owned.

ii. Pulmonary TB patients with other co morbidities.

\section{Sample Size Determination}

\section{Sample Size for Pulmonary TB Patient}

The sample size (n) was calculated using the formula $[10,11]$

$$
\mathrm{n}=\frac{\mathrm{Z}^{2} \mathrm{pq}}{\mathrm{d}^{2}}
$$

Where;

$\mathrm{n}=$ minimum sample size 
$\mathrm{z}=$ standard normal deviate at $95 \%$ confidence interval (1.96)

$\mathrm{p}=$ proportion of $\mathrm{TB}$ patients with highest level of satisfaction in a previous study which is $82.5 \%(0.825)$ [12].

$\mathrm{q}=$ complementary probability of $\mathrm{p}(1-0.825)$ $=0.175$

$\mathrm{d}=$ degree of precision $(0.05)$

$\mathrm{n}=\frac{1.96^{2} \times 0.825 \times 0.175}{0.05^{2}}$ $=222+(10 \%$ of 222

for non-response) $=250$

Since the population of TB patients in Katsina state is less than 10,000. The formula for sample size when a proportion with a population < 10000 was used.

$\mathrm{nf}=\mathrm{n} / 1+(\mathrm{n}) /(\mathrm{N})^{12}$

Where;

$\mathrm{nf}=$ desired sample size when population is less than 10000

$\mathrm{n}=$ desired sample size when population is greater than 10000

$\mathrm{N}=$ estimate of the population $=2329$ [13]

$\mathrm{nf}=250 / 1+250 / 2329=225$

\section{Sampling Technique}

There are $160 \mathrm{PHC}$ facilities providing $\mathrm{TB}$ DOTS Services.

Only $20 \%$ were sampled because of limited time and resource.

$160 \times 20 / 100=32$.

\section{Selection of Health Facility}

A multi-stage sampling was be used to get the required sample size.

\section{Stage One: Selection of LGA}

From the list of all the $11 \mathrm{LGAs}$ in each of the senatorial zones, 3 LGAs per zone were randomly selected using balloting technique given 9 LGAs. Consequently, the following LGAs were selected; Katsina, Rimi, Mashi, Dutsi, Safana, Funtua, Dandume, Bakori and Danja LGA.

\section{Stage Two: Selection of Health Facilities Providing DOTS in each of the LGA}

The number of public health facilities providing TB DOTS varies from LGA to LGA; least is 3 and highest is 6 . Proportionate allocation was used to select 32 health facilities across the 9 selected LGAs.
Stage Three: This Involved the Selection of TB Patients and Health Care Workers

\section{Selection of TB Patients}

The National TB control programme provides central register for each LGA. The register contains names of all patients diagnosed and registered for treatment. The register was used to assign unique identification numbers to all patients. The TB central register was also used to determine the sampling frame for the study. All patients that met the inclusion criteria in the selected LGAs were identified in the central register. They were assigned serial numbers; sampling interval was determined by dividing the total number of eligible participants (760) by the sample size (225) to give an interval 3. The first number (patient) was selected randomly using a random number between 1 and 3 and subsequently every $3^{\text {rd }}$ patient was selected until required sample size was achieved.

\section{Study Instruments}

In the study, both qualitative and quantitative instruments were used.

\section{Quantitative Component}

\section{A. Checklist}

The health facility checklist was adopted from WHO and another study [14]. It contained 3 sections (A-C) covering the Staffing, materials and laboratory equipment.

\section{B. TB Patients' Questionnaire}

The questionnaire on TB patient's perception on DOTS services was a structured; pre-tested, interviewer administered questionnaire and was adapted from a patient satisfaction questionnaire guide and from previous studies [15]. The questionnaire had six sections (A to F) covering respectively (A) Socio-demographic characteristics of respondents, (B) Organizational issues, (C) Facility equipment and supply (D) Availability of service(E) Interpersonal qualities of service provider and (F) Professional competence of skill workers.

\section{Questionnaire for TBLS and Head of Health Facility of DOTS Centre}

The questionnaire for TB and leprosy supervisor and head of TB DOTS facility was semi- structured, pre-tested and selfadministered. It covered staff involved in TB 
DOTS, staff training, supervision, resources for TB diagnosis and treatment and availability of recording and reporting format.

\section{Pre-testing of Questionnaires}

In order to ascertain the validity and reliability of the tools (the questionnaires and the skills checklist), they were first pretested in another PHC Bakiyawa Batagarawa LGA, which had similar characteristics to clinics in the study of local government area but located in a different LGA. It was carried out by the researcher and research assistants. Relevant adjustments were made to the questionnaire based on the observations during the pre-test.

\section{Qualitative Components}

Data for the qualitative component was obtained via key informant interviews (KII) with the TB Control Officer.

The KII guide was developed based on the objectives of the study and was pre-tested by conducting a session with the PHC director in Batagarawa local government areas. Changes were made to the guides after the pre-test.

\section{Data Collection}

Quantitative data collection was conducted by a team of six trained research assistants who were community health workers under close supervision. The service of two supervisors was sought who were medical doctors in the department of Community Medicine ABUTH Zaria, and they checked each completed questionnaire for completeness and consistency. Training of research assistants on quantitative data collection was conducted by the researcher for 2 days.
Qualitative data collection was done by the lead researcher as the moderator and one of the research assistants (as the note taker) who was trained to collect qualitative data.

\section{Measurement of Variables}

Scoring criteria for health facility assessment in PHC facilities implementing TB DOTS Strategy.

Where a parameter was observed a score of one was given but a score of zero was awarded for a parameter that was not observed.

\section{Statistical Analyses}

The questionnaires were checked for accuracy and completeness. The data was analysed using IBM SPSS statistics 20. Descriptive summary statistics such as mean and standard deviation were computed for continuous variables (age of patients, age of health workers, duration of stay in health facility, time spent before reaching health facility and duration of time since commencement of treatment) and proportions for categorical variables (sex, occupation, educational status, designation and overall satisfaction) of the respondents. Data presentation formats in graphical and tabular forms were drawn as appropriate. Cross tabulations were constructed between sociodemographic variables of patients and satisfaction and knowledge of TB and demographic characteristics of health workers. Chi-square test was used to assess statistical associations between proportions of respondents and scores for different variables.

For the qualitative aspect, content analysis was done for key informant interview.

Table 1. Socio Demographic Variable of Respondents

\begin{tabular}{|l|l|l|}
\hline Socio demographic characteristics & Frequency & Percent (\%) \\
\hline Age range & 7 & 3.1 \\
\hline $15-19$ & 16 & 7.1 \\
\hline $20-24$ & 35 & 15.6 \\
\hline $25-29$ & 33 & 14.7 \\
\hline $30-34$ & 31 & 13.8 \\
\hline $35-39$ & 26 & 11.6 \\
\hline $40-44$ & 18 & 8.0 \\
\hline $45-49$ & 19 & 8.4 \\
\hline $50-54$ & 40 & 17.8 \\
\hline $55+$ & \multicolumn{2}{|l|}{} \\
\hline Sex & 158 & 70.2 \\
\hline Male & \multicolumn{2}{|l|}{} \\
\hline
\end{tabular}




\begin{tabular}{|c|c|c|}
\hline Female & 67 & 29.8 \\
\hline \multicolumn{3}{|l|}{ Marital Status } \\
\hline Married & 150 & 66.7 \\
\hline Single & 51 & 22.7 \\
\hline Divorced & 8 & 3.6 \\
\hline Widowed & 16 & 7.1 \\
\hline \multicolumn{3}{|l|}{ Educational Status } \\
\hline No formal education & 111 & 49.3 \\
\hline Primary & 37 & 16.4 \\
\hline Secondary & 65 & 28.9 \\
\hline Tertiary & 12 & 5.3 \\
\hline \multicolumn{3}{|l|}{ Occupation } \\
\hline Farming & 67 & 29.8 \\
\hline Schooling & 20 & 8.9 \\
\hline unemployed & 28 & 12.4 \\
\hline Civil servant & 15 & 6.7 \\
\hline Trading & 66 & 29.3 \\
\hline Artisan & 11 & 4.9 \\
\hline Others & 18 & 8.0 \\
\hline
\end{tabular}

Table 2. Indices of Utilization of TB DOTS in PHC Facilities in Katsina State

\begin{tabular}{|l|l|l|}
\hline Variable & Frequency & Percent (\%) \\
\hline Duration of treatment & 128 & 56.9 \\
\hline Less than 3 months & 97 & 43.1 \\
\hline More than 3 months & \multicolumn{2}{|l|}{} \\
\hline Have easy access to Health facility & 220 & 98.5 \\
\hline Yes & 5 & 1.5 \\
\hline No & 141 & 46.2 \\
\hline Time taken to reach health facility \\
\hline Less than 30 min & 50 & 16.4 \\
\hline 30 minutes to 60 min & 34 & 37.4 \\
\hline More than 1 hour & 185 \\
\hline Cost incurred during treatment & 82.2 \\
\hline Yes & 40 & 17.8 \\
\hline No & 169 & 91.4 \\
\hline Reason for incurring cost & 11 & 5.9 \\
\hline Transport & - & - \\
\hline Food & 5 & 2.7 \\
\hline Provider's fee & \multicolumn{2}{|l|}{} \\
\hline Laboratory services &
\end{tabular}




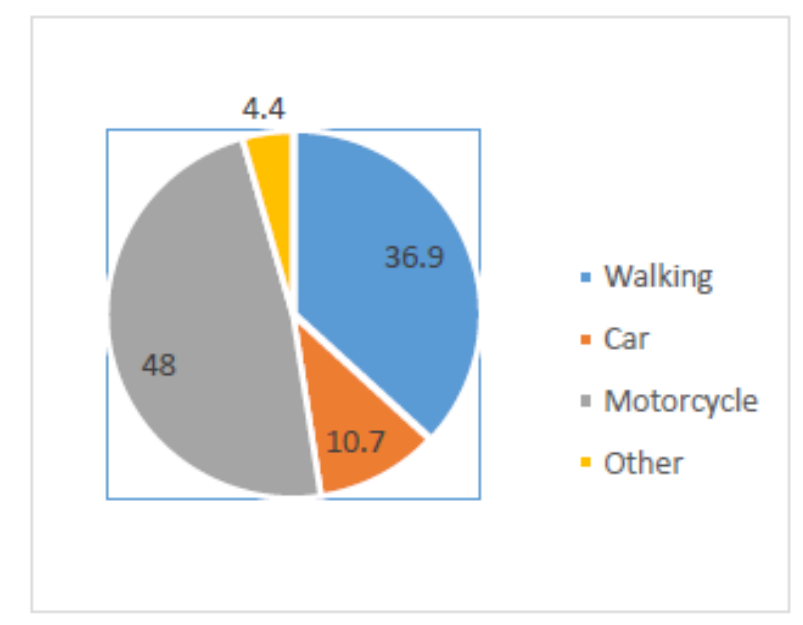

Figure 3. Mode of Transportation by Patients to Access TB Treatment in PHC Facilities in Katsina State

Table 3. Materials for Diagnosis and Treatment of TB in PHC Facilities in Katsina State

\begin{tabular}{|l|l|l|}
\hline Availability of Materials (N=32) & Frequency & Percent (\%) \\
\hline Latest version of NTLCP manual & \multicolumn{1}{l|}{} \\
\hline Available \& in use & 6 & 18 \\
\hline Not available & 26 & 82.2 \\
\hline Latest version of NTLCP Laboratory manual & 1 & 3.2 \\
\hline Available \& in use & 1 & 3.2 \\
\hline Available \& not in use & 30 & 93.6 \\
\hline Not available & \multicolumn{2}{|l|}{} \\
\hline Functional Weighing scale & 31 & 96.9 \\
\hline Available \& in use & - & - \\
\hline Available \& not in use & 1 & 3.1 \\
\hline Not available & 11 & 34.4 \\
\hline Microscope & 2 & 6.3 \\
\hline Available \& in use & 19 & 59.3 \\
\hline Available \& not in use & \multicolumn{2}{|l|}{} \\
\hline Not available & 11 & 34.4 \\
\hline Laboratory reagents & 2 & 6.3 \\
\hline Available \& in use & 19 & 59.3 \\
\hline Available \& not in use & 19 \\
\hline Not available & - & 59.4 \\
\hline Sputum collection container & 13 & - \\
\hline Available \& in use & 31 & 40.6 \\
\hline Available \& not in use & 96.8 \\
\hline Not available & \multicolumn{2}{|l|}{} \\
\hline Fixed Drug combination & \multicolumn{2}{|l|}{} \\
\hline
\end{tabular}

\section{Ethical Considerations}

Ethical approval was sought and obtained from the Ethical and Scientific Committee of the Katsina state ministry of health Ethics and Research Committee (MOH/ADM/1152/1/32). Informed written consent from the participants was obtained before participating in the study. Permission was obtained from Katsina state TB
Control Program. Confidentiality of the participants was ensured. No material reward was attached to the information provided by the participants.

\section{Results}

Most of the respondents were males (70.2\%), married (66.7\%) Muslim (92.4\%) with no formal 
education $(49.3 \%)$ and farming constitute the major occupation of the respondents is farming.

About half of the respondents had been on treatment for less than 3 months (56.9\%) and almost all the patients had easy access to treatment $(98.5 \%)$ with motorcycle as the commonest means of transport (48.0\%). Most of the patients had incurred cost $(82.2 \%)$ due to transport $(91.4 \%)$. Only $8 \%$ of the Health facilities had the latest program Manual, 96\% had functional weighting scale, $34.4 \%$ had microscope, $96.8 \%$ had anti-TB drugs.

\section{Discussion}

Knowledge of utilization of TB DOTS services by patients will provide an important input towards strengthening the services, especially in rural areas [16]. The study revealed that majority of the patients that utilized the services were males (70.2\%) and Muslims $(92.4 \%)$. This is similar to a study which found that larger number of males with pulmonary symptoms and new sputum smear-positive cases utilized RNTCP services than females in the ratio of 1.6:1 and 2.5:1 respectively. This was reported to be due to higher prevalence of persons with pulmonary symptoms and sputum positivity rate among males [16].

Most of the respondents (73.3\%) were able to reach the clinic easily. This is important because difficulty in reaching the health facility can lead to default in treatment. Most of the respondents reach the clinic by motorcycle $(45 \%)$ while $36.9 \%$ was by walking. The study further showed that $(82.2 \%)$ patients incurred cost during treatment and the main reason for incurring cost was transportation. There are several studies that showed that many patients were non-adherent to anti-TB drugs because of lack of money or perceived high cost of treatment, especially in resource-poor settings [17].

TB patients and households in sub-Saharan Africa often incurred high cost when utilizing TB treatment and care, both within and outside DOTS program. For many households, TB treatment and care related costs were considered being catastrophic because the cost incurred commonly amount to $10 \%$ or more per capita. A study in Bauchi, north east Nigeria, that costs of anti-tuberculosis treatment were expensive and potentially catastrophic for many patients and their families [18].
The findings in this study revealed that majority of the health facilities (75\%) had a designated staff assigned in the TB clinic. This is very important because it will help in reducing the waiting time before patients were seen by health care workers. A dedicated staff is also more likely to spend more time with the patients and this will greatly improve satisfaction and compliance with treatment.[19]. These findings contrast with studies from Nepal where human resources were scarce and drugs were in adequate [20]. The implication is that quality of services will be compromised and can lead to Multi drug resistance and consequent increase in morbidity and mortality.

Majority of the Health facilities (HF) had posters $(71.9 \%)$ in local languages, which is an important tool in Information education and communication. Weighting scales were also available in almost all the HF (96.9\%). However, findings from this study differ from a previous study where respondents reported a shortage of weighting scale [21]. This finding is similar to another study in South Africa where posters, sputum bottles \& gloves were available [21].

Lack of weighting scale can lead to under or overdose of anti-TB drugs; since TB drugs, dosage is based on body weight.

All the health facilities visited had drugs (anti-TB). This is very commendable because interruption of anti -TB drugs can lead to drug resistance. Every patient had his own drug kit, which his drugs were kept that the patient uses for the entire period of treatment. Studies in South Africa revealed that majority of HFs had drugs, only (3\%) of HFs experienced a shortage of drug in the last 2 months.

\section{Conclusion}

Our study revealed that resources for TB diagnosis were not adequate in most of the health facilities in Katsina state. However, resources for TB treatment were sufficient. The state government through the state ministry of health should provide more support in making TB resources adequate in all facilities so as to improve diagnosis.

\section{Acknowledgements}

We wish to acknowledge Katsina State Tuberculosis and Leprosy control Program. 


\section{References}

[1] WHO Global Tuberculosis control. Geneva, Switzerland: WHO; 2011. p.3.

[2] Corbett EL, Watt CJ, Walker N, Maher D, Williams BG, Raviglione $\mathrm{M}$, et al. The growing burden of tuberculosis: global trends and interactions with the HIV epidemic. Archives of Internal Medicine. 2003; 163(9):1009-21.

[3] Erah P, Ojieabu W. Success of the Control of Tuberculosis in Nigeria: A Review International Journal of Health Research. March 2009; 2(1):3-14.

[4] Salami T, Samuel S, Eze K, Oziogbe O. Tuberculosis in a Nigerian Teaching Hospital: Incidence and Pattern of distribution. Trop J Health Sci. 2007; 14(2):26-30.

[5] Nigerian Health Review 2007. Primary health Care in Nigeria:30 years after Alma Ata. Abuja, Nigeria: Health Reform Foundation of Nigeria; 2007. p. 12-8.

[6] Namadi A, Idriss H. Mid-term Evaluation of Katsina state TBL control program. Katsina: State ministry of health; 2009. p. 1-10.

[7] Federal Republic of Nigeria. 2006 Population and Housing Census. Priority Table Population Distribution by Age and Sex. Abuja, Nigeria: National Population Commission; April 2010. p. 190203.

[8] National TB and Leprosy Control Program. 2012 Annual statistics Nigeria. Federal ministry of health; 2012. p. 1.

[9] National TB and leprosy control programme workers manual. Revised 5th ed: Federal Ministry of Health Abuja Nigeria; September 2008. p. 110.

[10] Taofeeq I. Research Methodology and Dissertation Writing for Health and Allied Matters. Abuja, Nigeria: Cress Global link Limited Abuja; 2009. p. 113.

[11] Araoye MO. Research Methodology with statistics for Health and Social Sciences. Ilorin: Nathadex Publishers 2004. p. 118.

[12] Kamel MI, Rashed S, Foda NA, Mohie A, Loutfy M. Gender differences in health care utilization and outcome of respiratory tuberculosis in Alexandria. Eastern Mediterranean Health Journal. 2003; 9(4):741-56.
[13]National TB and Leprosy Control Program. Annual TB Statistics Nigeria. 2012. Girma A. Quality Assessment of Directly Observed Treatment ShortCourse of Tuberculosis in Afar National Regional State [Degree of Masters in Public Health]. Addis Ababa: Addis Ababa University; July, 2007. p.44-45. [14] Weis S. The effect of directly observed therapy resistance and relapse in tuberculosis. New England journal of medicine. 1994; 330 (17):1179-84.

[15] Ahmed J, Chadha V, Sing S, Venkatachalappa B, Kumar P. Utilization of RNTCP services in rural areas of Bellary District, Karnataka, by gender, age and distance from health centre. Indian journal of tuberculosis. 2009; 56(2):62-8.

[16] Umar N, Abubakar I, Fordham R, Bachmann M. Direct costs of pulmonary tuberculosis among patients receiving treatment in Bauchi State, Nigeria. Int J Tuberc Lung Dis 2012; 16(6):835-40.

[17] Barter DM AS, Murray MB, Bärnighausen T. Tuberculosis and poverty: the contribution of patient costs in sub-Saharan Africa--a systematic review. BMC Public Health. 2012; 12:980.

[18]Nezenga Z, Yohannes H, Tadese E. Patient satisfaction on tuberculosis treatment service and adherence to treatment in public health facilities of Sidama zone, South Ethiopia, BMC Health Services Research 2013; 13:110.

[19] Marahatta SB, Yadav RK, Giri D, Lama S, Rijal KR, Mishra SR, et al. (2020) Barriers in the access, diagnosis and treatment completion for tuberculosis patients in central and western Nepal: A qualitative study among patients, community members and health care workers. PLoS ONE 15 (1): e0227293. https://doi.org/10.1371/journal. pone.0227293.

[20] Tshitangano TG, Supa P, Karl P. Factors that Contribute to Tuberculosis Control in Primary Health Care Services at Mutale Primary Health Care SubDistrict of the Limpopo Province, South Africa. J Hum Ecol. 2010; 29(2):75-8.

[21] Okeibunor JC, Onyeneho NG, Chukwu JN, Post E. Barriers to Care Seeking in Directly Observed Therapy Short-Course (DOTS) Clinics and Tuberculosis Control in Southern Nigeria: A Qualitative Analysis. International Quarterly of Community Health Education 2007; 27(1):23-37. 